\title{
REVIEW ON TRANSDERMAL MICRONEEDLE-BASED DRUG DELIVERY
}

\author{
VALSA REMONY MANOJ*, HIMA MANOJ
}

Department of Biotechnology, Vel Tech Rangarajan Dr. Sagunthala R and D Institute of Science and Technology, Chennai, Tamil Nadu, India. Email: drmanojvr@veltech.edu.in

Received: 21 May 2018, Revised and Accepted: 29 August 2018

ABSTRACT

Drug delivery research extensively studies methods to transport proteins, deoxyribonucleic acid (DNA), genes, antibodies, and vaccines efficiently and safely to human bodies in recent years. This review comprehensively covers the developments in microneedle-based drug delivery, their configurations, design, fabrication, and operation. The factors surrounding the mechanical strength of microneedle-based transdermal patches (MNTP's) have also been reviewed. MNTP's can eliminate limitations of conventional drug delivery systems. Microneedle-based transdermal delivery approach will offer a self-management, patient-friendly, and efficient administration route for drug delivery.

Keywords: Microneedles, Transdermal patches, Insulin, Drug delivery.

(c) 2019 The Authors. Published by Innovare Academic Sciences Pvt Ltd. This is an open access article under the CC BY license (http://creativecommons. org/licenses/by/4. 0/) DOI: http://dx.doi.org/10.22159/ajpcr.2019.v12i1.27434

\section{INTRODUCTION}

Drug delivery research extensively studies methods to transport proteins, deoxyribonucleic acid (DNA), genes, antibodies, and vaccines efficiently and safely to human bodies in recent years. Conventional drug delivery approaches, such as oral administration and hypodermic injection, having their own limitations because a drug may be inactive through Phase I metabolism during oral delivery [1], while the hypodermic injection requires trained personnel [2]. To overcome these drawbacks, transdermal drug delivery can be opted as a safe, easily accessible, and patient-friendly approach [3]. A significant limitation to transdermal drug delivery is the inability of large biomolecules to passively diffuse through the dermal layers of skin due to their unfavorable hydrophilicity and macro size [4]. Microneedles, three-dimensional (3D) microstructures with microscale length (usually $<1000 \mu \mathrm{m}$ ), can pierce the stratum corneum and generate transient microchannels through which external molecules can passively diffuse into the skin. Microneedles could be designed in a manner that the penetration depth is superficial enough to not touch nerve receptors in the lower reticular dermis. This results in a painless drug administration. It is promising that this microneedle-based transdermal delivery approach will offer a self-management, patientfriendly, and efficient administration route for drug delivery [5] (Fig. 1).

\section{MICRONEEDLE STRUCTURE AND CONFIGURATION}

To ensure efficient drug delivery effect, microneedle chips are particularly designed to remain in a specific location; to maintain fluid communication with the tissues beneath the subcutaneous layer for an extended period of time. This is to remain conducive even when the skin is contoured and deformable. Earlier microneedle patches were made on a rigid and planar substrate made from silicon, stainless steel, or nickel was unable to effectively attach tightly onto the skin surface. Flexible microneedle patches have been developed to integrate polymer-based microneedles on a flexible substrate to be more pliable to the skin. Since fabricating tapered shape is not a standard process in the conventional MEMS technology, fabricating tapered microneedles using MEMS technology is the most critical part in a flexible microneedle patch [7].

In general, these microneedles can be categorized as solid microneedles, drug-coated microneedles, dissolving microneedles, and hollow microneedles. As shown in schematically in Fig. 2, each of these microneedles enables drug delivery by different mechanisms [8].

\section{Solid microneedles}

Solid microneedles are patterned into a sharp geometry which can be used to pierce the stratum corneum thus creating microchannels on the skin to allow the drug to diffuse through the microchannel. The drug is usually loaded onto a flexible substrate under the microneedle array. The microneedles penetrate into the skin and drugs uptake by capillaries for systemic treatment occurs when the flexible skin patch is applied on the skin.

\section{Polymer microneedles}

The development of polymer microneedles has focused on providing sufficient mechanical strength through different materials, including polylactic acid (PLA [9], polymethylmethacrylate [PMMA] [10] and maltose [12].

Polymer microneedles are normally patterned with the unconventional process due to their tapered 3D structures. The most common way for this tapered structure fabrication is inclined ultraviolet (UV) exposure technology [13]. When a photomask and a negative thick photoresist coated substrate are fixed together, its holding stage is tilted and rotated to a UV source. The reflected UV at the interface between the resist and the substrate is exploited as well as the incident UV. Except UV source, deep X-ray exposure is also deployed to fabricate the microneedle structures, known as the lithography, electroplating, and molding (LIGA) technique [14].

Due to the low optical absorption rate of the polymers, it can be used for the fabrication of polymer microneedles as tall as a few millimeters with a high aspect ratio using standard contact lithography equipment, which is a challenge in the UV range. Moreover, a two-photon initiated polymerization method [15] is utilized to fabricate the microneedles structure. A near-infrared ultra-short pulsed laser is focused into a photo curable resin to form 3D microstructures. For example, 3D grooveembedded microneedle has been reported to increase coating formulation amounts. To facilitate better drug targeting in the skin and to administer liquid coatings microneedles with pocketed structure can be used.

\section{Dissolving microneedles}

When compared with coated microneedles, polymer microneedles also have been developed in such a way that it can completely dissolve in the skin and thereby leave behind no biohazardous sharps waste after usage. For the designing of polymer microneedles biocompatible and 
water soluble materials, such as sugars, are used. And also, the dissolvable microneedles can penetrate skin surface as solid microneedles; drugs also can be mixed with the microneedle fabrication materials or encapsulated inside the microneedles to release into the skin.

Dissolving microneedles usually are fabricated by micro molds. Micro molds are filled with melted polymers with specified tapered structure. After these polymers are solidified in the mold, microneedles with sharp tips are integrated with drug formulations. Various materials including carboxymethylcellulose (CMC), chondroitin sulfate (polyvinylpyrrolidone, PLA copolymers), and fibroin have been deployed to fill into the mold cavities to form microneedles. Since the microneedles may not be entirely inserted into the skin, for higher efficiency, the drug is desired to be only encapsulated into the multiple-layered microneedles or adding an air bubble at the microneedle base tip part. It can be achieved by a particle-based molding method forming [17]

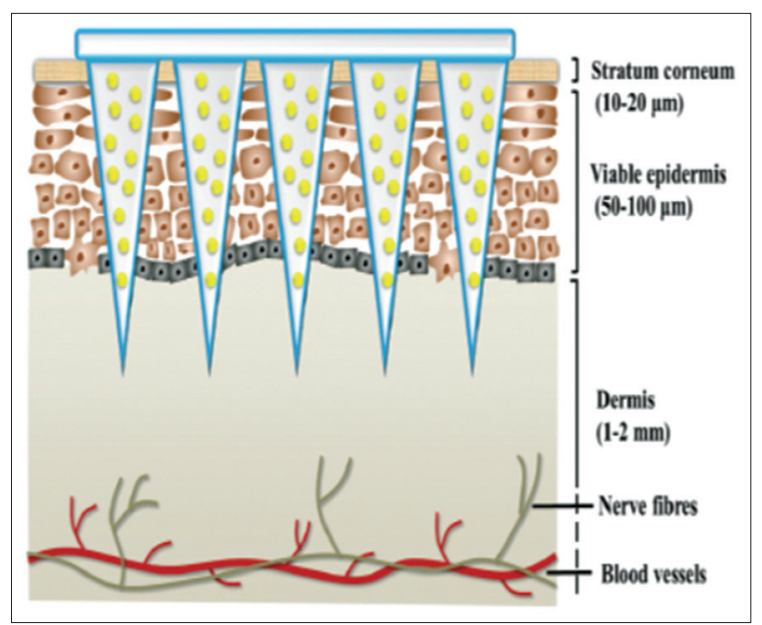

Fig. 1: Schematic illustration of transdermal drug delivery with the drug-containing microneedle array. The array pierces the stratum corneum and enables the drugs to enter the epidermis/ dermis layer without reaching the nerve fibers and blood vessels

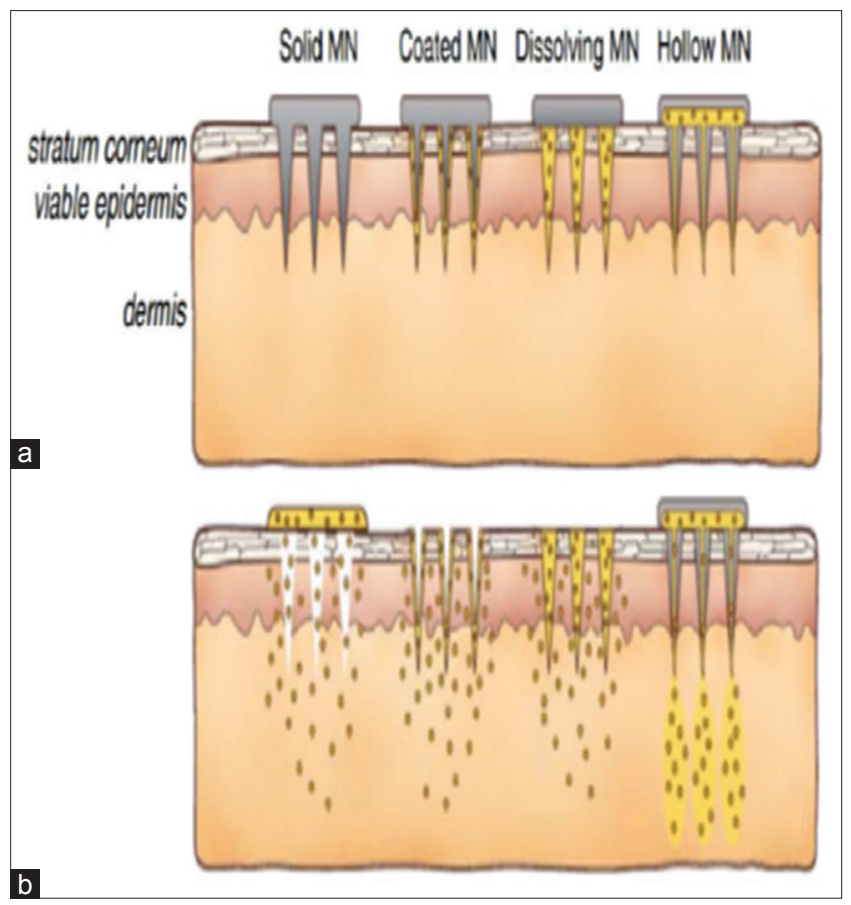

Fig. 2: (a and b) Microneedles with different structures and configurations
Hollow microneedles

Hollow microneedles provide a path for drug delivery into the skin or other tissues. The main advantage of hollow microneedles is that it allows pressure driven-flow of large dosage solution. Similar to conventional hypodermic injections, the pressure applied to hollow microneedles [32] can modulate drug flow rate. It enables a rapid bolus injection, a slow infusion or a time-varying delivery rate with a single flexible microneedle patch.

In general, there are two types of hollow microneedle designs.

- One mimics the traditional hypodermic needle with a single microneedle

- The other is an array of multiple hollow microneedle.

The advantage for hollow microneedle array device is that it can deliver.

Liquid formulation to a wide area and also enables a quicker delivery than subcutaneous injection. To make polymer hollow microneedles for flexible devices [36] have been fabricated directly from a rigid substrate using standard MEMS techniques including deep reactive ion etching, wet chemical etching and laser micromachining, and innovative fabrication methods are used.

By polymerization of liquid resin, a digital micromirror stereolithography instrument is used to fabricate hollow polymer microneedles. The

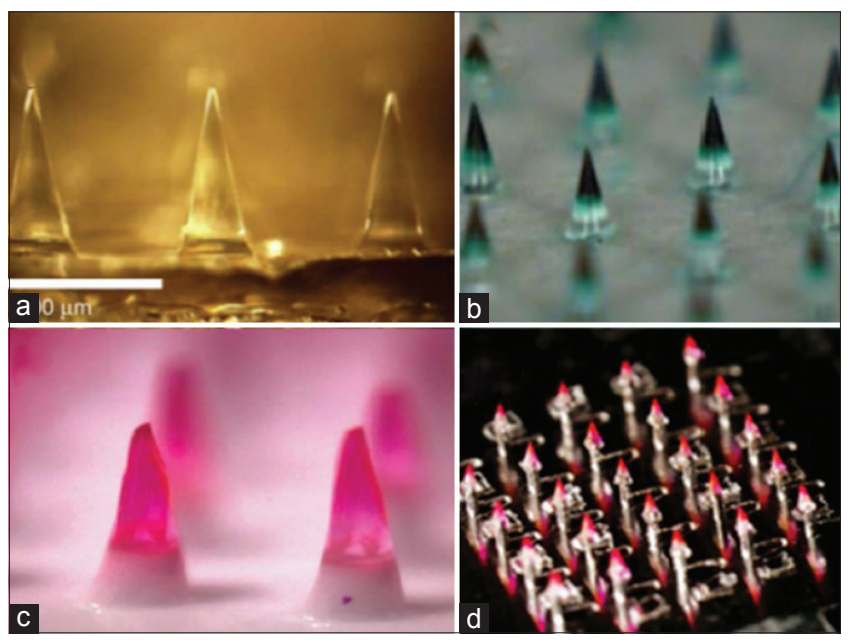

Fig. 3: (a-d) Dissolving microneedles

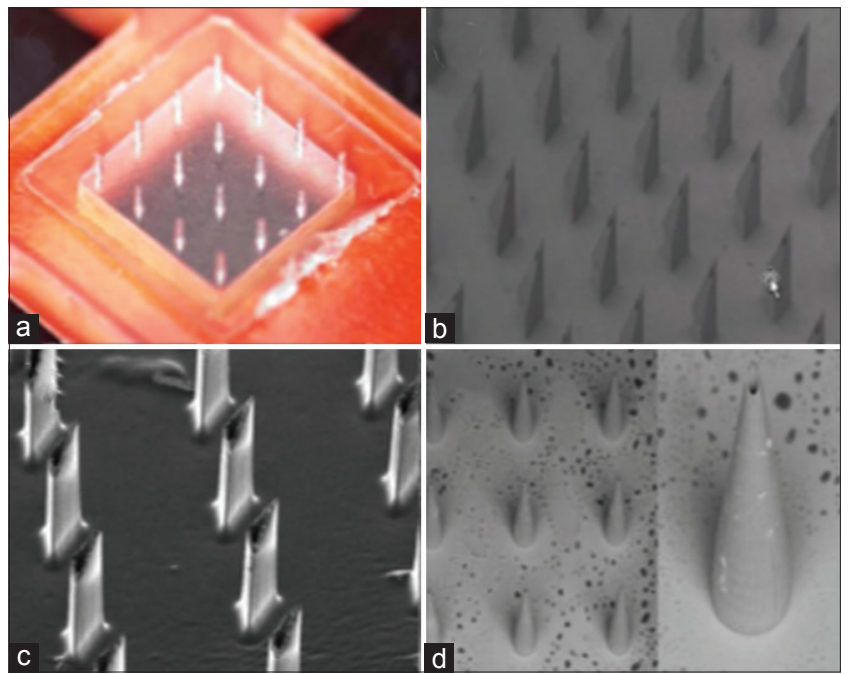

Fig. 4: (a-d) Hollow microneedles 
LIGA technique is utilized to form hollow microneedles by exposing X-ray through a mask onto PMMA. Direct low-photon polymerization in a laser-based rapid prototyping system is also used to form hollow polymer microneedles (Figs. 3 and 4).

\section{Theory of microneedle made by drawing lithography process}

To realize a 3D structure, to draw lithography technology is based on the viscous property of a polymer in the glass transition is used. The glass transition is a kinetic process between a solid state and liquid state of an amorphous polymer material. When a melted liquid polymer cools down, due to thermal molecular motions, it decreases the amorphous portion of the polymer gradually becoming a more viscous and glassy liquid. As temperature decreases below Tg, the glassy liquid turns into a solid state because of the structural rearrangements with little relative mobility (Fig. 5).

When a drawing plate is induced to form microneedles structure, drawing lithography is characterized by elastic deformation of polymer materials in the glassy transition. Initially, a polymer material with glassy state is placed between a substrate and drawing plate.

Subsequently, the polymer with glassy state is elongated by drawing the plate. A glassy structure is generated between the substrate and substrate. Since the gravitational force and inertial force are negligible, the geometry of the glassy structure is mainly modulated by the extensional strain force from the drawing plate and the fixed coating plate (Fig. 6). This glassy structure is stretched by the drawing plate and fixed coating plate from opposite directions. Since the contact area with coating plate is much larger than the contact area withdrawing plate, the stretching force is stronger from the fixed coating plate. As the drawing plate rise up, the glassy structure under the stretching force will extensional deform. The radius in the top curvature near the drawing plate is smaller than that near the fixed coating plate, which induces a wasp-waist shape bridge. As a result of the temperature gradient through the glassy structure and change of drawing speed, the difference of stretching force in the opposite directions become so

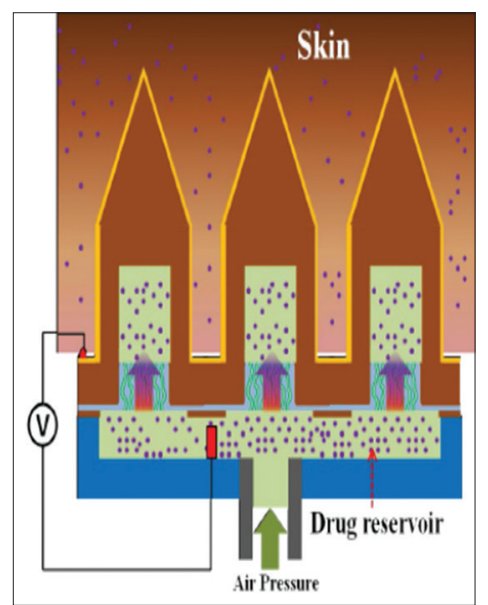

Fig. 5: Working principle of microneedle array in transdermal patches for transdermal drug delivery

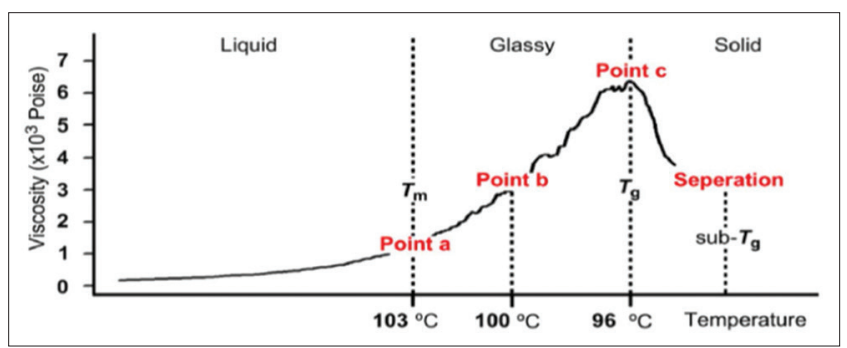

Fig. 6: Viscosity change with temperature and drawing point large that the extension deformation cannot remain a steady-state. The breakage of the glassy structure will form a tapered microneedle.

Previously, this drawing lithography process has been applied to fabricate 3 types of microneedles: Continuous drawing for an ultrahigh aspect ratio hollow microneedle, stepwise controlled drawing for a dissolving microneedle, and drawing with antidromic hybrid electromicroneedle (Fig. 7).

\section{Microneedle patch design objectives}

MNPs seek to achieve multiple design objectives to improve logistics and efficiency of drug delivery, as summarized in Table 1.

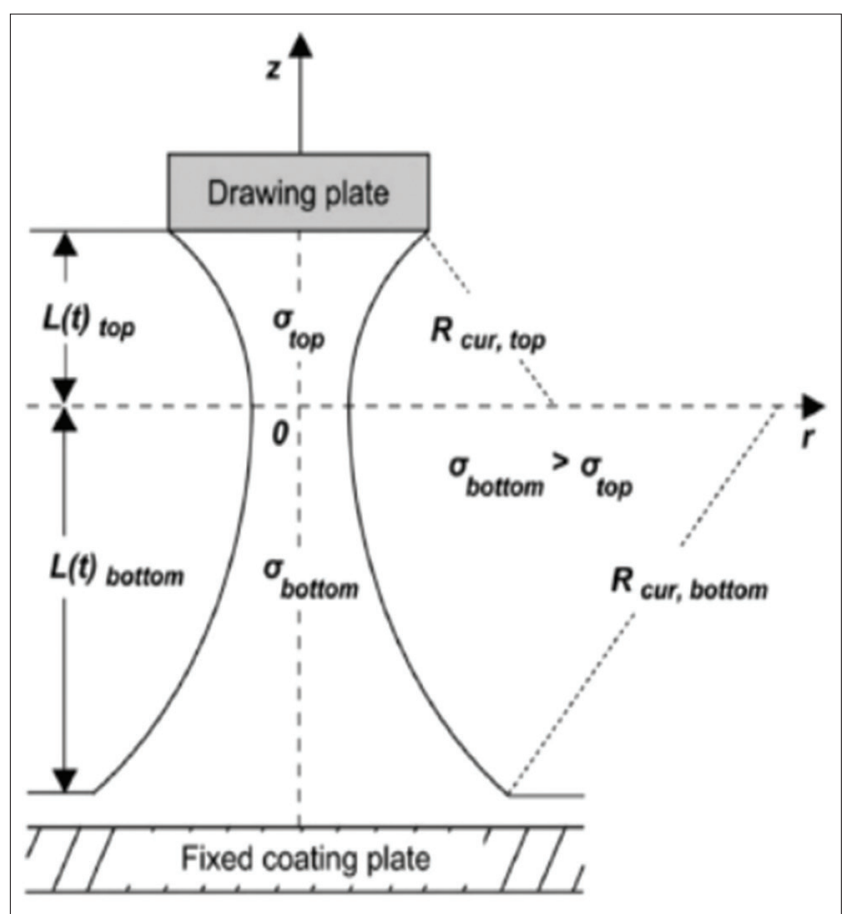

Fig. 7: Extensional deformation from the fixed coating surface in the glass transition. By the axial difference of surface tension, the position of narrow necking is situated in the upper part of the intermediate liquid bridge

Table 1: Microneedle patch design objectives

\begin{tabular}{ll}
\hline Design objects & Medical impact \\
\hline Drug delivered across skin's & Effective drug delivery
\end{tabular}

stratum corneum

Correct dose delivered

Targeted delivery to the skin

Reduced expertise needed for patch application Improved stability

Reduced or eliminated sharps waste

Single-use, single dose, fully

disposable

No need for reconstitution

Lack of pain

Delivery feedback

Reduced patch wear time

Reduced package size

Low-cost manufacturing
Effective drug delivery

Faster onset of systemic delivery of drugs improved immunogenicity of vaccines

Increased access to drug cost savings

Less reliance and cold chain storage and transportation

Increased safety reduced need for sharps waste disposal Increased safety reduced drug/vaccine wastage Increased safety reduced access to drug

Improved patient compliance Improved patient compliance Improved patient compliance Cost savings Cost savings 


\section{Drug delivery across skin's stratum corneum}

A primary goal in drug delivery to the skin is diffusion through the skin's outer layer of stratum corneum, which is $10-20 \mu \mathrm{m}$ thick at typical administration sites such as arm and leg transport of drugs into the skin. Conventional transdermal patches are limited to a small class of drugs that are able to cross the barrier for the drug delivery.

Therapeutic rates, through diffusion. Of suitable drugs are limited to low molecular weights (usually <350 Da) and are usually lipophilic in nature. Hypodermic needles very effectively cross the stratum corneum. Microneedles measuring hundreds of microns in length also effectively cross the stratum corneum in a minimally invasive manner compared to hypodermic injections.

\section{Targeted skin delivery}

By the alteration of skin access by different anatomy and physiology, the drug efficiency can be altered. For example, the drug administration through rich capillary bed in the superficial dermis and effective drainage of lymphatic fluids from skin give rapid access of drug to the systemic circulation. For the targets for vaccine delivery [71,77], the skin is a first line of defense against pathogen entry into the body and, therefore, has abundant populations of immune cells. Microneedles are measuring hundreds of microns to target the skin, which have 1-2 mm thick at typical administration sites.

\section{Reduced expertise needed}

MNPs reduce the expertise needed for the administration because they are simply pressed to the skin by hand or using a hand-held applicator [92,93]. For example, type 1 diabetes is trained to self-inject insulin because there is no other therapeutic option, but many type 2 diabetes is not put on GLP-1 receptor against drugs. The time in which when self-administration is not appropriate (e.g., mass vaccination campaigns), administration by lesser-trained personnel would increase access to otherwise-injectable medicines, which would be especially beneficial to the developing countries where trained health-care professionals are less in number. Finally, there should be cost savings associated with drug administration by lesser-trained personnel.

\section{Improved thermal stability}

Many drugs need constant refrigeration, including during transportation. This increases costs and complicates logistics, especially in developing countries where mechanisms to maintain refrigeration from manufacturer to patient (i.e., the "cold chain") are not always intact. In part because of their solid-state formulation, MNPs can provide increased stability without refrigeration, especially for biomolecules such as proteins and vaccines [98-105].

\section{Reduction or elimination of sharps waste}

Hypodermic injection of drugs generates biohazardous sharps waste such as used needles. It also poses a safety risk due to transmission of diseases by accidental or intentional reuse of needles. It also incurs additional costs and requires logistics for safe sharps disposal. Even when MNPs are difficult to administer unintentionally, cannot be easily reloaded with drug, and generate no sharps waste when water-soluble microneedles are used because the microneedles dissolve in the skin.

\section{Use and throw, disposable in nature}

MNPs as well as needles [95] and syringes are single use, single dose, and fully disposable, all of which reduce the risk of disease transmission associated with medical equipment reuse. However, drug and vaccine vials are sometimes multiuse and multidose. This can lead to vaccine wastage fully disposable MNPs avoid this complexity.

\section{No addition needed}

Some drugs are lyophilized to increase stability during storage, but water must be added to reconstitute them into a liquid form before injection. Reconstitution adds time and complexity and requires expertise to prevent potential mistakes with serious medical consequences. MNPs capture the stability advantages of a dry formulation and do not need to be reconstituted because they are reconstituted" by the skin's fluids on patch application.

\section{Lack of pain and needle phobia}

Pain from injections can be an impediment to patient adherence with therapy [107]. Because microneedles are small, they do not hurt and

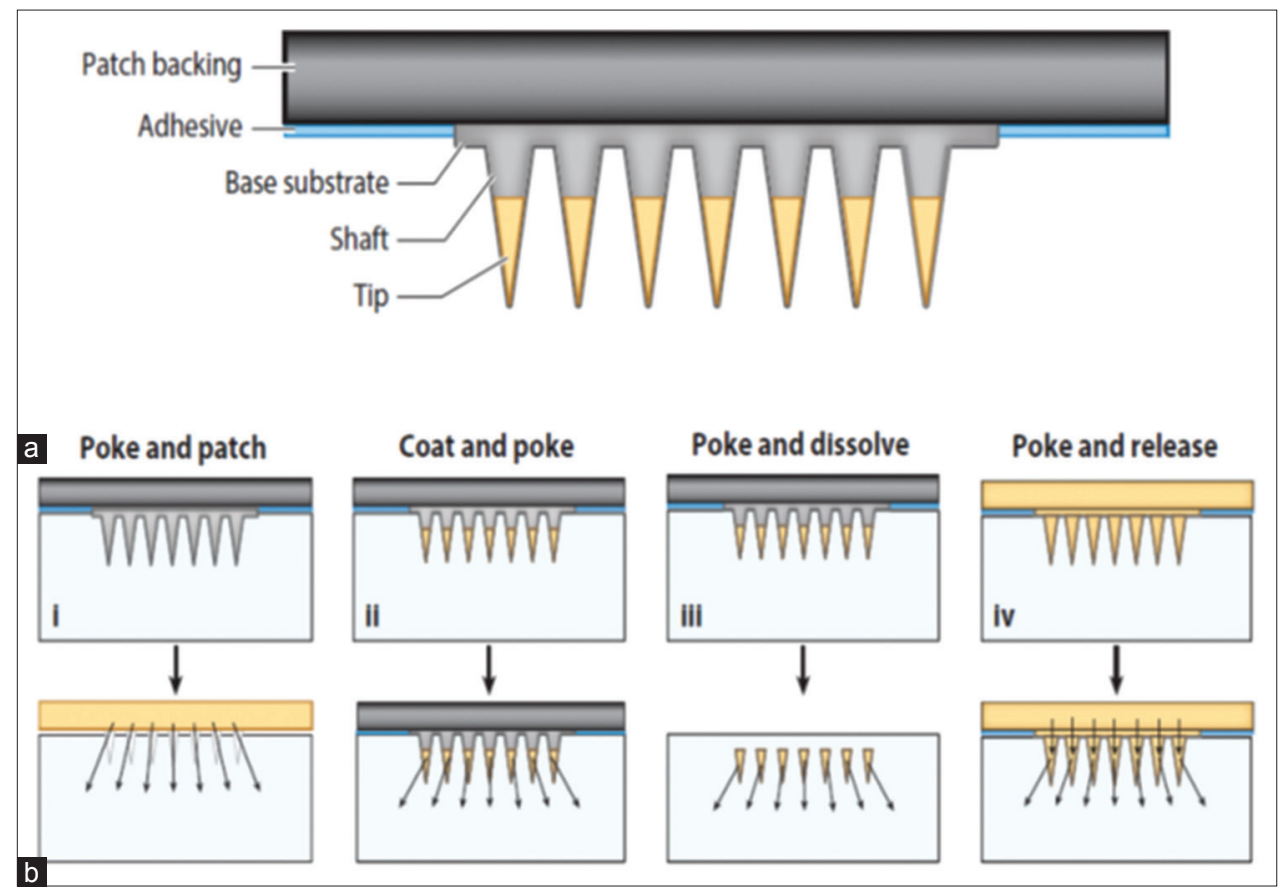

Fig. 8: (a and b) Microneedle patch operations 
therefore are better accepted by patients. In addition, fear of hypodermic needles is widespread and can be a barrier to patients' accessing health care [108]. Since microneedles are typically in a patch form, needle phobia should not affect patient acceptance in drug delivery technology.

\section{Delivery feedback}

Patients generally know when they successfully swallowed a pill or completed an injection. Similarly, MNPs would benefit to notify patients that the patch has been applied correctly and successfully punctured the skin and delivered their payload.

\section{Reduced patch wear time}

Swallowing a pill or giving an injection can be completed within seconds. Reducing patch wear time would shorten the time required to administer the drug and thereby should increase patient compliance [110].

\section{Package size small}

Pills require little space per dose, but injectable drugs require much more space because they contain a large amount of water in addition to the active pharmaceutical ingredient. MNPs have no water and have reduced needle phobia. Thus, they can be more space efficient, which can reduce storage, transportation, and disposal costs.

\section{Low-cost manufacturing}

MNPs can be expected to be competitive with injectable drugs in terms of manufacturing costs.

\section{MNP design and operation}

Microneedles are varying with the design and features even when there are several features. They contain an array of thousands of microneedles with a sharp tip of 100 to $1000 \mu \mathrm{m}$ in length. Microneedle can be made up of different material such as silicon, metal, or polymer according to the type of microneedle and drug is placed on the tip of the needle or coated around the microneedle or loaded on the microneedle as the type of microneedle such as coated microneedles, hollow microneedles, polymer microneedles, and solid microneedles.

Microneedles are mounted as an array on a base substrate, often made of the same material as the microneedles. The microneedle array is, in turn, attached to a patch backing that often has a skin an adhesive to facilitate use. MNP's can be used in multiple ways for drug delivery (Fig. 8). The poke and patch approach involves skin pretreatment by puncturing the skin with microneedles that do not contain the drug. A drug-loaded patch (or other topical formulation) is then placed over the treated area for slow drug release through the residual microneedle pores [79,111-113]. The patch may be of a design similar to conventional transdermal patches and may incorporate agents to help keep the pores open for a longer time to extend the duration of drug delivery [114].

The drug can also be placed in or on the microneedle tip and is then actively deposited in the skin on microneedle insertion. In the coat and poke approach, the drug is coated on the microneedle surface in a water-soluble matrix that dissolves off the microneedles into the skin $[74,80]$.

Microneedle patches (MNP) designs and operations.

a. Microneedles comprise a shaft and tip that often encapsulates or is coated with a drug. The microneedle array is mounted on a base substrate that is attached to patch backing to facilitate handling and skin adhesion.

b. Drug delivery approaches for MNP use. MNPs can be used as a pretreatment, after which a (i) drug formulation is placed on the skin surface for slow drug release through residual pores in the skin (poke and patch); (ii) be coated with drug in a water-soluble matrix that is released in the skin (coat and poke); (iii) encapsulate drug in water-soluble microneedles that dissolve in the skin (poke and dissolve); or (iv) encapsulate drug in the patch backing and, in some cases, the microneedles that slowly release drug through the non-water-soluble microneedle matrix (poke and release).

Various approaches used by the microneedles are:

a. Poke and dissolve approach: It uses microneedles that are watersoluble and encapsulation of drug within the microneedle matrix for the purpose of microneedles to dissolve into the skin and release their encapsulated drug.

b. Poke and release approach: With this method, drugs are encapsulated in the patch backing and, in some cases, the microneedles to enable slow drug release while the patch is adhered to the skin. The patch and microneedles are often made of hydrogels that swell on contact with the fluids of the skin, thereby enabling the drug to diffuse out of the backing through the microneedles and into the skin.

\section{MNP design parameters}

There are multiple MNP design parameters that affect patch performance, such as microneedle and patch geometry and materials.

\section{Microneedle and patch geometry}

The geometry of individual microneedles and the overall patch can affect MNP performance. Microneedles are typically 100-1,000 $\mu \mathrm{m}$ long. When applied quasi-statically to the skin (e.g., by hand), longer microneedles facilitate more reliable skin insertion to overcome skin deformation that can result from short microneedles simply bending the skin surface without penetrating. However, longer microneedles can cause increased pain. Microneedle width (at the base) is typically between $50 \mu \mathrm{m}$ and $300 \mu \mathrm{m}$, with aspect ratios ranging between 2:1 and 10:1. Wider microneedles and smaller aspect ratios provide increased strength that prevents microneedle fracture or, more typically, deformation. However, wider microneedles are harder to penetrate deeply into the skin and can increase pain $[60,61]$. Some microneedles taper continuously from a wide base to a sharp tip, which increases the mechanical strength needed to support polymer microneedles $[57,62]$. Other microneedles have parallel walls along much of the shaft and then taper only close to the tip. This latter design can often be strong enough for metal or silicon microneedles, but sometimes not for polymer microneedles.

Microneedle tips are often in the range of $1-10 \mu \mathrm{m}$, which is usually sufficiently sharp to enable skin insertion. Tips may be less sharp, and in some cases (notably for etched silicon microneedles), tip sharpness can be well below $1 \mu \mathrm{m}$. Microneedles are assembled into arrays that typically range from tens to tens of thousands of microneedles. Array area is often in the $1-10-\mathrm{cm}^{2}$ range. This can result in a wide range of microneedle densities [37]. A large microneedle density (i.e., requiring thinner and, therefore, shorter microneedles) can suffer from the "bed-of-nails" effect, where the insertion force is distributed among too many microneedles so that none penetrate the skin. This may be overcome by having sharper tips and stronger insertion forces. Smaller microneedle density makes skin insertion easier and accommodates wider and, therefore, longer microneedles, but the smaller number of microneedles typically reduces the amount of drug that can be delivered. Increasing microneedle array area accommodates more microneedles but can increase pain. More importantly, greater array area makes microneedle insertion into skin surfaces, which are typically non-planar and deformable, more difficult. The overall size of the MNP is typically larger than the microneedle array in part to provide an additional surface area for the skin adhesive and in part to make the patch sufficiently large for easy handling by patients.

\section{MNP materials}

MNP must satisfy multiple criteria that vary depending on the patch design and among the patch components. The microneedles have to be sufficiently strong to puncture the skin. They should also have to be biocompatible, which are suitable for manufacturing processes and inexpensive. For the non-dissolving microneedles, it is often 
accomplished using a metal such as stainless steel and titanium, polymers such as polycarbonate and polymethyl methacrylate, polyvinyl pyrrolidone, and silicon. The drug is typically present in a water-soluble matrix that dissolves in the skin. This matrix is not only biocompatible but also suitable for delivery into and clearance from the body. This usually means, at a minimum, the matrix must be on the FDA's. It also should be water-soluble and, when rapid onset of drug delivery is desirable, exhibit rapid dissolution in the skin. The material should have to be compatible with the drug it encapsulates during manufacturing, storage, and delivery. When this matrix is used as a coating on microneedles, it must form films on the microneedles that remain adherent during storage and skin insertion and should be amendable to coating processes. When this matrix forms the microneedle (i.e., dissolving microneedles), then it must also satisfy the mechanical strength requirement to make a strong microneedle. Materials that are often used as water-soluble matrices include polymers that help provide mechanical strength and/ or viscosity during coating such as carboxymethyl cellulose, methyl cellulose, polyvinyl pyrrolidone [25], polyvinyl alcohol, hyaluronic acid, and chondroitin sulfate and can stabilize sensitive biomolecules during the manufacturing process.

In some cases, microneedles (and backing) are made of swellable hydrogels that release the encapsulated drug on gel hydration. Materials such as poly(methyl vinyl ether-comaleic acid) crosslinked with poly(ethylene glycol) have been used. Work has also been done to develop microneedles as slow-release devices made out of biodegradable polymers such as polylactic coglycolic acid and silk [67].

\section{Fabrication of MNP'S}

The introduced microneedles are silicon microneedles which are first prepared at the year 1990. When micro fabrication technology had advanced to the point that making microneedle-like structures was relatively straightforward. Many additional methods have been developed to meet the needs of pharmaceutical manufacturing.

\section{Microneedle structures and molds fabrication}

Fabrication of the microneedles is the main part in the MNP fabrication [72]. Microneedle structures are often fabricated using metal, silicon, or non-dissolving polymer and by poke and patch, as well as coat and poke devices. Microneedle structures are also used as masters to make molds that are used to fabricate poke and dissolve as well as poke and release MNPs.

Silicon microneedles are often made using (deep) reactive ion etching [79]. In this method, photolithographic methods are typically employed to define the microneedle spacing and base size, and plasma chemistry can be adjusted to alter the profile of the microneedle as it tapers to a sharp tip. It provides good control over microneedle shape but also requires significant method optimization. Reactive ion etching is being used to make extremely short (e.g., $100 \mu \mathrm{m}$ ) and sharp microneedle arrays for vaccine delivery targeted to the skin's epidermis [74].

Wet etching of silicon is also used (e.g., in a bath of potassium hydroxide), where photolithographic methods, as well as silicon crystal planes, define the microneedle shapes [72].

\section{Silicon etching typically produces microneedles pointing out of the substrate plane.}

Laser cutting has also been used to make microneedles. Similar to wet etching, microneedles are made from metal sheets, but the cutting is done using an Nd: YAG laser, for example, that "draws" the shapes of the microneedles without the need for a mask. Laser-cut microneedles often require electropolishing to remove rough edges. Laser ablation (e.g., $\mathrm{CO}_{2}$ laser) has also been used to make inverse molds of microneedle arrays by "drilling" tapered holes into polymer sheets [132].

Polymer microneedles can be made using various methods most commonly involving casting liquid solution(s) onto an inverse mold of the MNP that is often made of polydimethylsiloxane to dissolving microneedles, hydrogel microneedles, and, in some cases, coated microneedles. After drying, the MNP is peeled out of the mold. MNPs made in this way have been studied for influenza vaccination in clinical trials $[100,103]$. Two-photon polymerization has also been used to make polymer microneedles [120].

\section{MNP use}

MNP's are designed in such a way that it has to maintain stability during storage, be correctly applied for skin insertion, deliver drug at the right dose and kinetics in the skin, and be designed for safe disposal after use.

\section{Drug and vaccine stability in or on microneedles}

MNPs need to be stored under conditions that maintain drug activity, microneedle integrity (e.g., sharp, strong, and not bent with coating intact), and cleanliness (e.g., sterility). This is accomplished not only through MNP design but also through packaging that provides physical protection from mechanical damage and environmental contamination. Storage at appropriate temperature and humidity (e.g., using desiccant) also contributes. Drugs have also been studied for their stability when formulated into MNPs [91]. Human growth hormone retained most of its activity after storage for 15 months at room temperature using a CMC/trehalose formulation. Parathyroid hormone formulated in sucrose, EDTA, $\mathrm{HCl}$, and polysorbate 20 on coated MNPs was stable for 2 years without refrigeration, but sterilization by gamma irradiation before storage was associated with reduced drug stability over time.

\section{MNP skin application}

The complete success of the MNP's can be achieved by the reliable drug delivery with high patient acceptance with less pain. By the slow insertion by hand, the skin is highly elastic, which results in significant stretch/deformation of the skin before penetration.

The various ways to overcome this limitation include using longer microneedles (i.e., approaching $1 \mathrm{~mm}$ in length. This approach may, therefore, be coupled with having drug only near the microneedle tip, so drug toward the base of the microneedle is not wasted because it does not enter the skin. A significant advantage is low-velocity insertion that it enables hand application of the MNP, which thereby avoids the cost, size, and complexity of a high-velocity applicator.

Using shorter microneedles (e.g., 100-300 $\mu \mathrm{m}$ in length) and/or more completely penetrating microneedles into the skin requires dynamic insertion of the microneedles at high velocity (e.g., $3 \mathrm{~m} / \mathrm{s}$ ) such that the higher strain rate of application increases the skin's instantaneous stiffness. Microneedle geometry must also be optimized to allow for plastic engagement of the shorter microneedles [123] with the skin, which also mitigates the bed of nails effect. A drawback of this approach, however, is the necessity of a high-velocity applicator to achieve this engagement with the skin consistently. Yet, despite the various microneedle designs and insertion devices that have been studied, complete microneedle skin insertion is not usually achieved (Fig. 9).

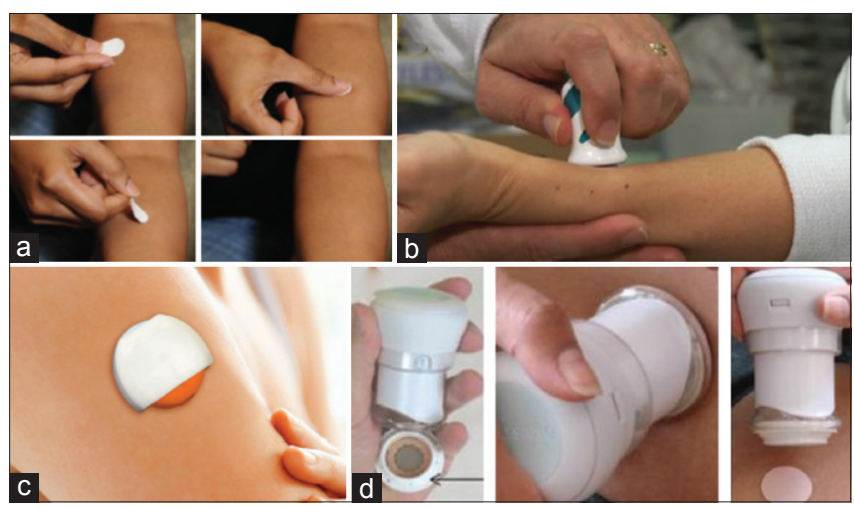

Fig. 9: (a-d) Microneedle patches application in the skin 


\section{Transport of molecules in the skin after MNP delivery}

Following microneedle penetration into the skin, a substantial length of the microneedles is suddenly immersed in a wet cellular environment within the skin where the dry-formulated drug needs to become wet and dissolve. The ideal dissolution characteristics are dependent on the desired pharmacokinetics of the drug and its desired mode of action within the skin $[7,69]$. For coated or dissolving microneedles, minimizing the amount of time the patch remains on the skin is desirable to improve patient acceptance and reduce the likelihood of premature patch removal. Between 2 and 20 min are often required, although rapid mechanical separation of a drug-loaded "arrowhead" from a microneedle shaft has yielded 1-s patch removal times.

Faster drug dissolution times, which correspond to shorter patch wear times, may be limited in part by the dissolution characteristics of the drug, but can be modulated by the dissolution characteristics of the formulation matrix the drug is in. In fact, the drug and formulation matrix does not need to be fully dissolved before patch removal; they just need to be sufficiently dissolved or hydrated, so the microneedle coating or dissolving microneedle matrix remains in the skin when the patch is removed. This observation has also enabled formulations for extended drug release (even after short patch wear times) because formulations deposited in the skin by the microneedles could form a depot for slow drug release. Another approach to achieve short patch wear times is to minimize the amount of material to be dissolved and gives it a large surface-to-volume ratio. This can be achieved by thinner microneedles or microneedle coatings but often needs to be balanced with delivering a given dose, which may call for larger masses of drug and excipient [62]. Once the drug has dissolved in the skin, it diffuses away from the site of delivery. For systemic uptake in the bloodstream, the drug should most likely diffuse to capillaries. Since capillaries are in high abundance in the superficial dermis, rates of uptake for various drugs after MNP administration are faster compared with rates after subcutaneous injection. In contrast, vaccine delivery is often targeted to the skin's abundant resident immunological cells, so rapid diffusion away from the site of administration may not be desirable. This type of skin vaccination has enabled improved immune responses (compared with standard needle and syringe injection into a muscle), as shown by vaccine dose sparing [65], greater longevity of immunity, and greater breadth of immunity. The ideal deposition site and duration of vaccine residence in the skin are not fully understood and remain subjects of investigation.

\section{Disposal of MNP patch}

In some cases, when the drug delivery is not $100 \%$ efficient the safe disposal of microneedle patches important which is coming into the category of residual drug, biohazards, and sharp waste. However, in that cases, there may be dangers of residual drug exposure to others, including children, animals, and the environment, or there may be illicit use of the residual drug if, for example, it is a drug of addiction. Used MNPs are likely considered biohazardous waste because they contact bodily fluids like interstitial fluid of the skin. However, the amount of bodily fluid is probably small which is even less than the blood found on a used adhesive bandage. Used MNPs are considered sharps waste. Dissolving MNPs are likely not considered sharps waste because they contain no microneedles after use. Nondissolving such as coated microneedles may be considered sharps waste, although the hazard they pose is different from that of used hypodermic needles or scalpel blades and may, therefore, be handled differently. In all these cases, safe disposal may be facilitated through suitable waste streams such as placement in sharps containers or biohazard bags and/or through suitable packaging after use.

Drug/vaccine MNP delivery outcomes in terms of pharmacodynamics or pharmacokinetics

MNPs have been developed for delivery of dozens of different drugs in preclinical studies, and a few of them have been evaluated in clinical trials. Most studies have compared that the pharmacokinetics and pharmacodynamics of drug delivery to the skin are using MNPs to drug delivery to the muscle or subcutaneous space by hypodermic injection. The objective of either has been to show the similarity between the two routes of administration or improvements such as faster uptake of drug into the bloodstream, increased vaccine immunogenicity which is enabled by the MNP.

\section{Vaccines}

In addition to logistical and delivery advantages, MNP vaccination also offers improved immunogenicity [75-77]. Skin vaccination using MNP targets resident immune cells, such as epidermal Langerhans cells and dermal dendritic cells, and can be enhanced by circulating immune cells recruited to the site. There is also extensive fluid transport from the skin to the draining lymph nodes. Slow release of vaccines also increases immunogenicity.

The studies are going on in MNP vaccines such as diphtheria, chikungunya, and anthrax. These vaccines have also been immunogenic in animal models, including mice, rats, guinea pigs, rabbits, pigs, and macaques. The immune responses from both human and cellular have been measured which are often show a proof, of which is superior to hypodermic injection. Some vaccination literature has emphasized the use of extremely dense arrays of microneedles (e.g., $10,000 / \mathrm{cm}^{2}$ ) designed to kill cells in the epidermis at the site of each microneedle penetration. This approach deposits the vaccine in a local milieu of immunogenic signals released from dying and dead cells which can further enable significant vaccine dose control over the body by the MNP's [76-80].

\section{Drugs}

Although vaccines have received more attention in the literature, small-molecule and peptide drugs have progressed further into clinical translation.

Drugs have also been administered for local effects. These include drugs for photodynamic therapy and local skin anesthesia and also phenylephrine to treat fecal incontinence through local delivery near the anal sphincter.

Biotherapeutics have been administered using MNPs. Insulin has received considerable attention for bolus, basal, and glucoseresponsive delivery to the skin. Other peptide and protein drugs include erythropoietin, heparin, leuprolide acetate, desmopressin, and human growth hormone [96]. Additional studies have administered plasmid DNA and small interfering RNA using MNPs.

\section{Pharmaceutical}

MNP's playing a major role in the field of the medical field but it also has applications in the cosmetic types also. The first microneedle is cylindrical. The original purpose of these devices was to promote collagen production in the skin in response to the micro-injuries caused by the microneedles and thereby improve skin. They can be marketed in combination with topical formulations, for example, for microneedle pre-treatment that facilitates entry of materials applied to the skin. Dissolving microneedles made of hyaluronic acid have also been marketed for cosmetic purposes. On the basis of the success of intradermal hyaluronic acid injections used as fillers to combat the effects of aging on the skin. These products entered the marketplace more than 10 years ago and are gaining popularity. Such pharmaceutical products can eventually be integrated into the digitalization and automation processes involved in drug discovery and manufacture [125].

Safety

The development of MNP's is mainly occurred for the increased safety purposes. However, from the safety profiles from clinical trials and other human studies typically show only mild, transient erythema at the site of patch application as the most common side effect. Numerous studies have shown that microneedles cause little or no pain in human 
subjects. The possibility of infections occurring at the site of MNP application has received only limited attention, but infections have not been reported in human studies. Cosmetic microneedle roller devices are used repeatedly by the same person and are not sterilized between uses; this practice does not appear to cause infection, although no studies have been performed to look specifically at this question. Even when MNP's generate sharp waste; they may be less hazardous than hypodermic needles.

\section{Characterization studies}

\section{Mechanical strength of the microneedles}

To study the mechanical strength of the MNP's, both the adequate adhesion property between the tip and microtubes, and the sufficient stiffness of the microtubes for successful penetration, were studied. As shown in Fig. 10a, Instron Microtester 5848 (Instron, USA) was used for the stiffness testing. A typical result was shown in Fig. 10b. During the testing, the breakage of microneedles only occurred at the interface when the exerting load was larger than the threshold value. However, the SU-8 microtubes were strong enough to stand the pressure. After characterization of 20 samples, the average threshold value was $7.36 \pm 0.48 \mathrm{~N}$ for the microneedles $(300 \mu \mathrm{m}$ at microneedle base and $1000 \mu \mathrm{m}$ high). Since the minimal force required for a successful penetration was reported to be $<1 \mathrm{~N}$ with the similar microneedle dimension [54], the device was reliable during the penetration process.

\section{Characterization of penetration (Fig. 11)}

To check whether the maltose tips could be dissolved once inserted in the tissue, four chips with the same maltose tips height were inserted into the skin and taken out one by one with 3 min interval. Maltose tips were gradually dissolved versus increased time as shown in Fig. 12b. After $9 \mathrm{~min}$, the maltose tips were totally dissolved, and the lumens of SU-8 microtubes were observed from the top view. Different from the traditional dissolvable needles which encapsulated drugs into the needles, this microneedle array was expected to allow large volume of drugs to pass through the remaining SU-8 microtubes inside the skin.

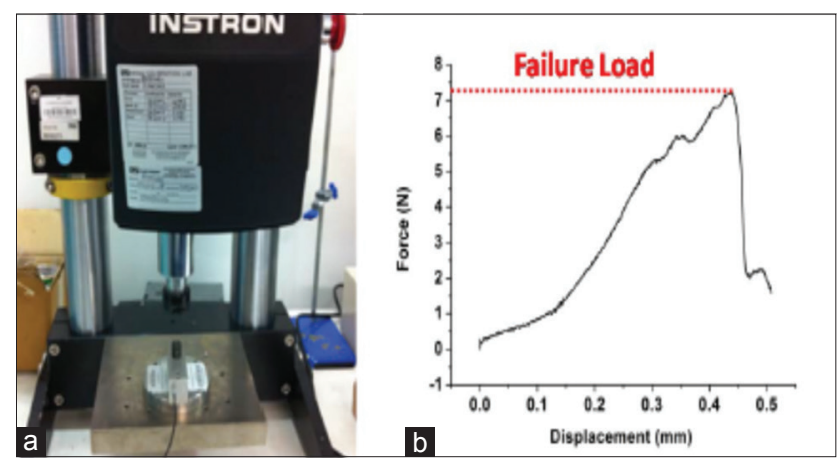

Fig. 10: (a) Testing setup for the microneedle mechanical testing. (b) A typical microneedle stiffness testing result

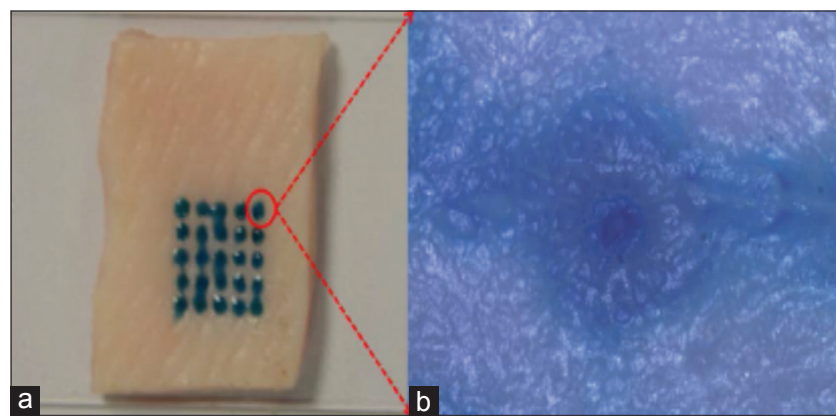

Fig. 11: (a and b) Penetration testing results on the porcine cadaver skin
Blue dyed water was ejected through the lumens in microneedle to the beaker containing fresh water such that we could demonstrate the hollow microneedle formed in individual microtube during the fabrication process. This microfluidic testing was performed in fresh water as shown in Fig. 13. Visual inspection of the ejection proved that there was no blockage inside the microtubes. Due to the good bonding quality between each layer, there was no obvious damage on the device in this experiment even though the syringe pump was increased to its maximum speed at $3.3 \mathrm{~mL} / \mathrm{min}$ for $6 \mathrm{~mL}$ syringe.

To verify that the drug solution can be delivered into tissue, a fluorescent solution was delivered through the microneedles after the insulin were dissolved. The representative results were then investigated through a
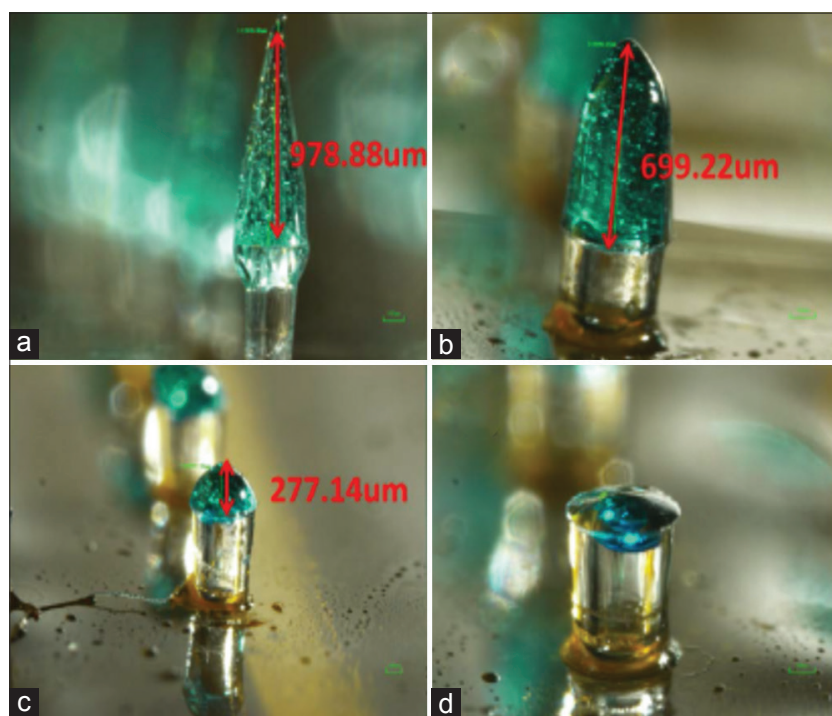

Fig. 12: Maltose tips dissolving process. (a) The original sharp maltose tip. (b) Maltose tip after inserted into skin for $3 \mathrm{~min}$ (c) $6 \mathrm{~min}$ and (d) $9 \mathrm{~min}$
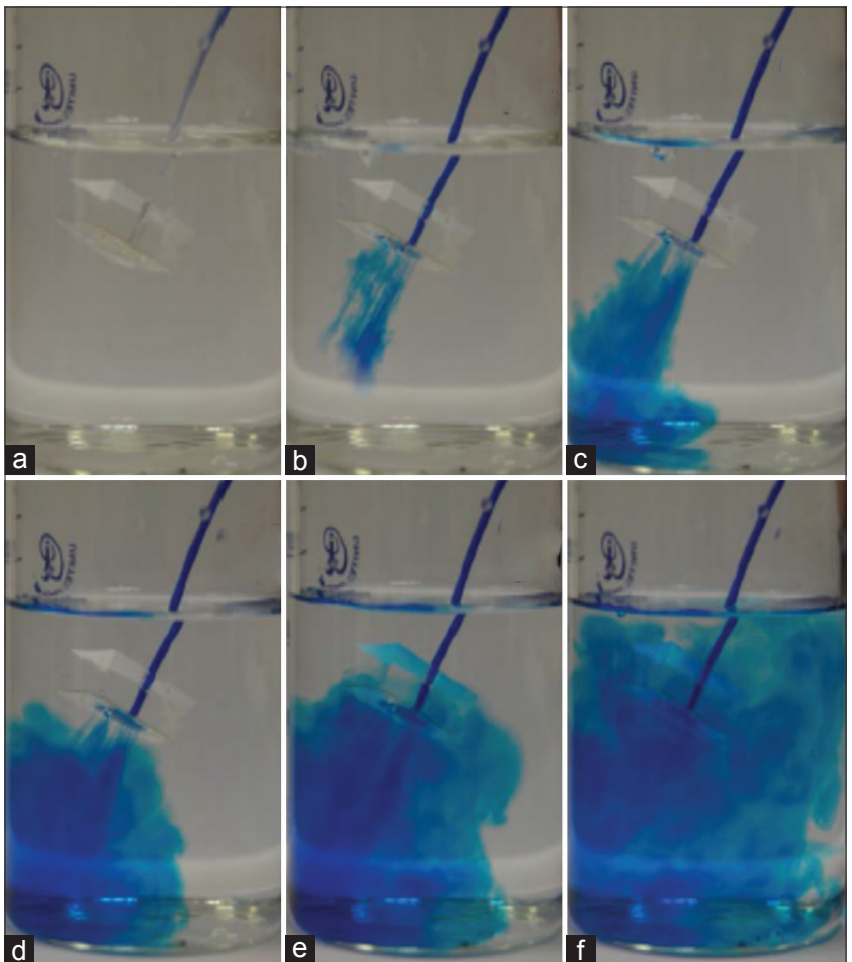

Fig 13: (a-f) Microfluidic testing for SU-8 microtubes 

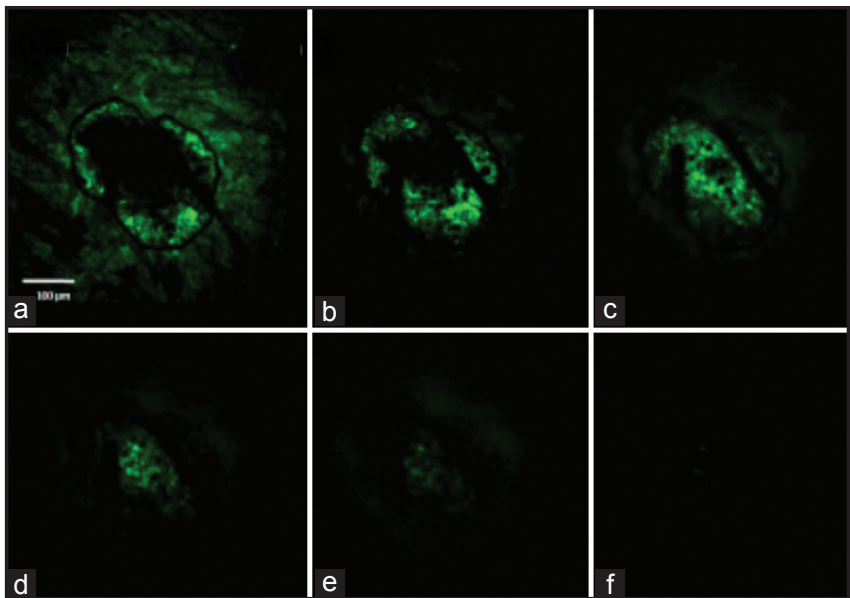

Fig. 14: Images of confocal microscopy of the site where one microneedle inserted is a proof for fluorescent solution is delivered into the tissue underneath the skin surface. Optical section depths are (a) $30 \mu \mathrm{m}$, (b) $60 \mu \mathrm{m}$, (c) $90 \mu \mathrm{m}$, (d) $120 \mu \mathrm{m}$,

(e) $150 \mu \mathrm{m}$, and (f) $180 \mu \mathrm{m}$ below the skin surface

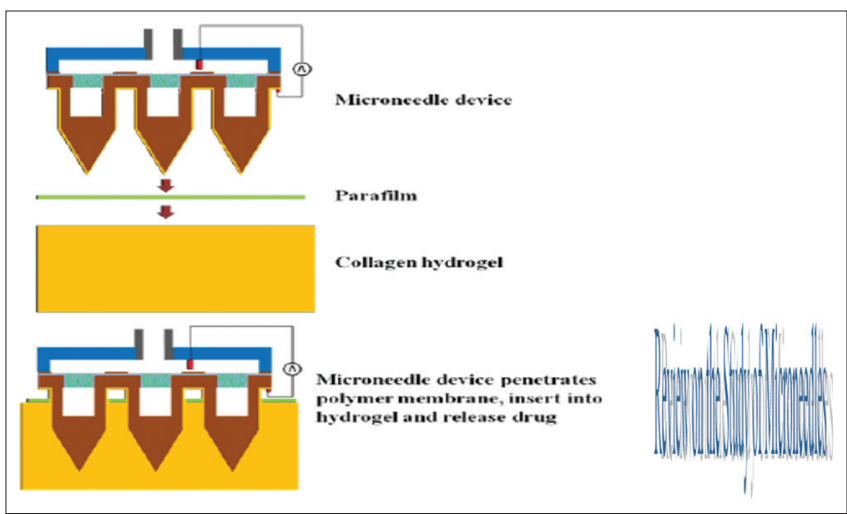

Fig. 15: Scheme describing experimental setup to test the microneedle device in an in vitro

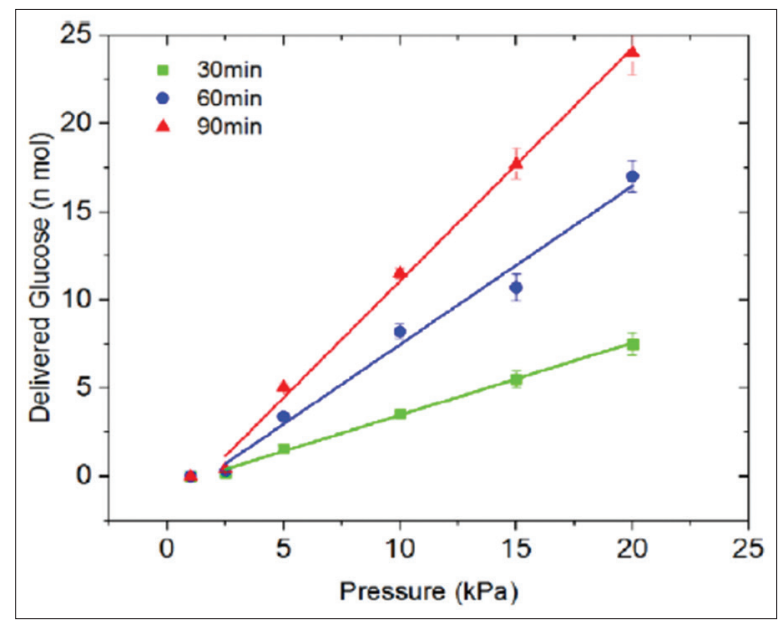

Fig. 16: Glucose delivery quantity as a function of pressure

confocal microscopy (Fig. 14). The permeation pattern of the solution along the microchannel confirms the solution delivery results. The black area served as a control area without any diffused solution. In contrast, the tissues stained by fluorescence illustrated the diffused area. The focus depth was up to $180 \mu \mathrm{m}$ with the interval of $30 \mu \mathrm{m}$. Since the microchannel was created by the conical shaped tips, the diameter of the microchannel decreased as the focus depth increases. The following diffusion area was dependent on the microchannel dimension and also decreased accordingly Mironeedles penetrate parafilm and collagen hydrogel to subsequently deliver drugs with controlled pressure and electric field (Figs. 15 and 16).

In the test of glucose delivery, glucose solution was delivered into the collagen slab under different pressure and duration. Then, the collagen slabs were digested in $1 \mathrm{mg} / \mathrm{mL}$ collagenase at room temperature. It will take around $1 \mathrm{~h}$ for all the collagen slabs to be fully digested. The solution was collected to measure the glucose concentration with glucose detection kit. By comparing the readings from the kit with the measured concentration standard curve, the concentration of the glucose in hydrogel was measured. Such studies are crucial to the evaluation of Diabetes patients [126,127].

\section{CONCLUSION}

MEMS is a rapidly growing in its range of applications, particularly in the medical field. Microneedle-based transdermal patches (MNTP) are an example. Microneedles are 3D microstructures with microscale length of usually $<1000 \mu \mathrm{m}$. They can pierce the stratum corneum and generate transient microchannels through which external molecules can passively diffuse into the skin. MNTP's can eliminate the limitations of conventional drug delivery systems. Microneedle-based transdermal delivery approach will offer a self-management, patient-friendly, and efficient administration route for drug delivery.

\section{AUTHORS CONTRIBUTION}

Concept and collection of data - Hima Manoj. Writing the article and critical review of article - Valsa Remony Manoj.

\section{CONFLICTS OF INTEREST}

Nil.

\section{REFERENCES}

1. Singh R, Singh S, Lillard JW Jr. Past, present, and future technologies for oral delivery of therapeutic proteins. J Pharm Sci 2008;97:2497-523.

2. Nir Y, Paz A, Sabo E, Potasman I. Fear of injections in young adults: Prevalence and associations. Am J Trop Med Hyg 2003;68:341-4.

3. Prausnitz MR, Langer R. Transdermal drug delivery. Nat Biotechnol 2008;26:1261-8.

4. Finnin BC, Morgan TM. Transdermal penetration enhancers: Applications, limitations, and potential. J Pharm Sci 1999;88:955-8.

5. Donnelly RF, Raj Singh TR, Woolfson AD. Microneedle-based drug delivery systems: Microfabrication, drug delivery, and safety. Drug Deliv 2010;17:187-207

6. Sivamani RK, Stoeber B, Wu GC, Zhai H, Liepmann D, Maibach H, et al. Clinical microneedle injection of methyl nicotinate: Stratum corneum penetration. Skin Res Technol 2005;11:152-6.

7. Kim YC, Park JH, Prausnitz MR. Microneedles for drug and vaccine delivery. Adv Drug Deliv Rev 2012;64:1547-68.

8. van der Maaden K, Jiskoot W, Bouwstra J. Microneedle technologies for (trans)dermal drug and vaccine delivery. J Control Release 2012; 161:645-55.

9. Choi CK, Kim JB, Jang EH, Youn YN, Ryu WH. Curved biodegradable microneedles for vascular drug delivery. Small 2012;8:2483-8.

10. Moon SJ, Lee SS. A novel fabrication method of a microneedle array using inclined deep x-ray exposure. J Micromech Microeng 2005; 15:903.

11. Yoon YK, Park JH, Allen MG. Multidirectional UV lithography for complex 3-D MEMS structures. Microelectromech Syst J 2006; $15: 1121-30$

12. Kolli CS, Banga AK. Characterization of solid maltose microneedles and their use for transdermal delivery. Pharm Res 2008;25:104-13.

13. Han M, Lee W, Lee SK, Lee SS. 3D microfabrication with inclined/ rotated UV lithography. Sens Actuators A Phys 2004;111:14-20.

14. SugiyamaS, Khumpuang S, Kawaguchi G. Plain-pattern to crosssection transfer (PCT) technique for deep x-ray lithography and applications. J Micromech Microeng 2004;14:1399. 
15. Lee KS, Kim RH, Yang DY, Park SH. Advances in 3D nano/ microfabrication using two-photon initiated polymerization. Prog Polym Sci 2008;33:631-81.

16. Han M, Hyun DH, Park HH, Lee SS, Kim CH, Kim C. A novel fabrication process for out-of-plane microneedle sheets of biocompatible polymer. J Micromech Microeng 2007;17:1184.

17. Park JH, Choi SO, Seo S, Choy YB, Prausnitz MR. A microneedle roller for transdermal drug delivery. Eur J Pharm Biopharm 2010;76:282-9.

18. Choi SO, Kim YC, Park JH, Hutcheson J, Gill HS, Yoon YK, et al. An electrically active microneedle array for electroporation. Biomed Microdevices 2010;12:263-73.

19. Ameri M, Fan SC, Maa YF. Parathyroid hormone PTH(1-34) formulation that enables uniform coating on a novel transdermal microprojection delivery system. Pharm Res 2010;27:303-13.

20. Christodoulou KN, Kistler SF, Schunk PR. Advances in computational methods for free-surface flows. In: Liquid Film Coating. Netherlands: Springer; 1997. p. 297-366.

21. Gill HS, Prausnitz MR. Coated microneedles for transdermal delivery. J Control Release 2007;117:227-37.

22. DeMuth PC, Su X, Samuel RE, Hammond PT, Irvine DJ. Nano-layered microneedles for transcutaneous delivery of polymer nanoparticles and plasmid DNA. Adv Mater 2010;22:4851-6.

23. Han M, Kim DK, Kang SH, Yoon HR, Kim BY, Lee SS, et al. Improvement in antigen-delivery using fabrication of a grooves-embedded microneedle array. Sens Actuators B Chem 2009; $137: 274-80$

24. Gill HS, Prausnitz MR. Pocketed microneedles for drug delivery to the skin. J Phys Chem Solids 2008;69:1537-41.

25. Raphael AP, Prow TW, Crichton ML, Chen X, Fernando GJ, Kendall MA, et al. Targeted, needle-free vaccinations in skin using multilayered, densely-packed dissolving microprojection arrays. Small 2010;6:1785-93.

26. Ito Y, Hagiwara E, Saeki A, Sugioka N, Takada K. Sustained-release self-dissolving micropiles for percutaneous absorption of insulin in mice. J Drug Target 2007;15:323-6.

27. Sullivan SP, Murthy N, Prausnitz MR. Minimally invasive protein delivery with rapidly dissolving polymer microneedles. Adv Mater 2008;20:933-8.

28. Park JH, Allen MG, Prausnitz MR. Polymer microneedles for controlled-release drug delivery. Pharm Res 2006;23:1008-19.

29. You X, Chang JH, Ju BK, Pak JJ. Rapidly dissolving fibroin microneedles for transdermal drug delivery. Mater Sci Eng: C 2011;31:1632-6.

30. Park JH, Choi SO, Kamath R, Yoon YK, Allen MG, Prausnitz MR, et al. Polymer particle-based micromolding to fabricate novel microstructures. Biomed Microdevices 2007;9:223-34.

31. Fukushima K, Ise A, Morita H, Hasegawa R, Ito Y, Sugioka N, et al. Two-layered dissolving microneedles for percutaneous delivery of peptide/protein drugs in rats. Pharm Res 2011;28:7-21

32. Chu LY, Choi SO, Prausnitz MR. Fabrication of dissolving polymer microneedles for controlled drug encapsulation and delivery: Bubble and pedestal microneedle designs. J Pharm Sci 2010;99:4228-38.

33. Lee JW, Park JH, Prausnitz MR. Dissolving microneedles for transdermal drug delivery. Biomaterials 2008;29:2113-24.

34. Sullivan SP, Koutsonanos DG, Del Pilar Martin M, Lee JW, Zarnitsyn V, Choi SO, et al. Dissolving polymer microneedle patches for influenza vaccination. Nat Med 2010;16:915-20.

35. Chu LY, Prausnitz MR. Separable arrowhead microneedles. J Control Release 2011;149:242-9.

36. Wonglertnirant $\mathrm{N}$, Todo $\mathrm{H}$, Opanasopit $\mathrm{P}$, Ngawhirunpat $\mathrm{T}$, Sugibayashi K. Macromolecular delivery into skin using a hollow microneedle. Biol Pharm Bull 2010;33:1988-93.

37. Davis SP, Martanto W, Allen MG, Prausnitz MR. Hollow metal microneedles for insulin delivery to diabetic rats. IEEE Trans Biomed Eng 2005;52:909-15

38. Burton SA, Ng CY, Simmers R, Moeckly C, Brandwein D, Gilbert T, et al. Rapid intradermal delivery of liquid formulations using a hollow microstructured array. Pharm Res 2011:28:31-40.

39. Clements CJ, Larsen G, Jodar L. Technologies that make administration of vaccines safer. Vaccine 2004;22:2054-8.

40. Gill HS, Prausnitz MR. Does needle size matter? J Diabetes Sci Technol 2007;1:725-9.

41. Hogan ME, Kikuta A, Taddio A. A systematic review of measures for reducing injection pain during adult immunization. Vaccine 2010;28:1514-21.

42. Vicente-Pérez EM, Quinn HL, McAlister E, O’Neill S, Hanna LA,
Barry JG, et al. The use of a pressure-indicating sensor film to provide feedback upon hydrogel-forming microneedle array self-application in vivo. Pharm Res 2016;33:3072-80.

43. Birchall JC, Clemo R, Anstey A, John DN. Microneedles in clinical practice - an exploratory study into the opinions of healthcare professionals and the public. Pharm Res 2011;28:95-106.

44. Mikolajewska P, Donnelly RF, Garland MJ, Morrow DI, Singh TR, Iani $\mathrm{V}$, et al. Microneedle pre-treatment of human skin improves 5-aminolevulininc acid (ALA)- and 5-aminolevulinic acid methyl ester (MAL)-induced ppIX production for topical photodynamic therapy without increase in pain or erythema. Pharm Res 2010;27:2213-20.

45. Ding Z, Verbaan FJ, Bivas-Benita M, Bungener L, Huckriede A, van den Berg DJ, et al. Microneedle arrays for the transcutaneous immunization of diphtheria and influenza in BALB/c mice. J Control Release 2009;136:71-8

46. Wermeling DP, Banks SL, Hudson DA, Gill HS, Gupta J, Prausnitz MR, et al. Microneedles permit transdermal delivery of a skin-impermeant medication to humans. Proc Natl Acad Sci U S A 2008;105:2058-63.

47. Brogden NK, Banks SL, Crofford LJ, Stinchcomb AL. Diclofenac enables unprecedented week-long microneedle-enhanced delivery of a skin impermeable medication in humans. Pharm Res 2013;30:1947-55.

48. Haj-Ahmad R, Khan H, Arshad MS, Rasekh M, Hussain A, Walsh S, et al. Microneedle coating techniques for transdermal drug delivery. Pharmaceutics 2015;7:486-502.

49. Gill HS, Prausnitz MR. Coated microneedles for transdermal delivery. J Control Release 2007; 117:227-37.

50. Edens C, Collins ML, Goodson JL, Rota PA, Prausnitz MR. A microneedle patch containing measles vaccine is immunogenic in non-human primates. Vaccine 2015;33:4712-8

51. DeMuth PC, Li AV, Abbink P, Liu J, Li H, Stanley KA, et al. Vaccine delivery with microneedle skin patches in nonhuman primates. Nat Biotechnol 2013;31:1082-5

52. Kommareddy S, Baudner BC, Oh S, Kwon SY, Singh M, O'Hagan DT, et al. Dissolvable microneedle patches for the delivery of cell-culturederived influenza vaccine antigens. J Pharm Sci 2012;101:1021-7.

53. Lee JW, Park JH, Prausnitz MR. Dissolving microneedles for transdermal drug delivery. Biomaterials 2008;29:2113-24.

54. Donnelly RF, Singh TR, Garland MJ, Migalska K, Majithiya R, McCrudden CM, et al. Hydrogel-forming microneedle arrays for enhanced transdermal drug delivery. Adv Funct Mater 2012;22:4879-90.

55. Singh TR, Dunne NJ, Cunningham E, Donnelly RF. Review of patents on microneedle applicators. Recent Pat Drug Deliv Formul 2011;5:11-23

56. Davis SP, Landis BJ, Adams ZH, Allen MG, Prausnitz MR. Insertion of microneedles into skin: Measurement and prediction of insertion force and needle fracture force. J Biomech 2004;37:1155-63.

57. Ita K. Reflections on the insertion and fracture forces of microneedles. Curr Drug Deliv 2017; 14:357-63.

58. Crichton ML, Ansaldo A, Chen X, Prow TW, Fernando GJ, Kendall MA, et al. The effect of strain rate on the precision of penetration of short densely-packed microprojection array patches coated with vaccine. Biomaterials 2010;31:4562-72.

59. Yan G, Warner KS, Zhang J, Sharma S, Gale BK. Evaluation needle length and density of microneedle arrays in the pretreatment of skin for transdermal drug delivery. Int J Pharm 2010;391:7-12.

60. Gill HS, Denson DD, Burris BA, Prausnitz MR. Effect of microneedle design on pain in human volunteers. Clin J Pain 2008;24:585-94.

61. Haq MI, Smith E, John DN, Kalavala M, Edwards C, Anstey A, et al. Clinical administration of microneedles: Skin puncture, pain and sensation. Biomed Microdevices 2009;11:35-47.

62. Park JH, Allen MG, Prausnitz MR. Biodegradable polymer microneedles: Fabrication, mechanics and transdermal drug delivery. Conf Proc IEEE Eng Med Biol Soc 2004;4:2654-7.

63. Lutton RE, Moore J, Larrañeta E, Ligett S, Woolfson AD, Donnelly RF, et al. Microneedle characterisation: The need for universal acceptance criteria and GMP specifications when moving towards commercialisation. Drug Deliv Transl Res 2015;5:313-31.

64. Raphael AP, Crichton ML, Falconer RJ, Meliga S, Chen X, Fernando GJ, et al. Formulations for microprojection/microneedle vaccine delivery: Structure, strength and release profiles. J Control Release 2016;225:40-52.

65. Mistilis MJ, Bommarius AS, Prausnitz MR. Development of a thermostable microneedle patch for influenza vaccination. J Pharm Sci 2015; 104:740-9.

66. Lee JW, Han MR, Park JH. Polymer microneedles for transdermal drug delivery. J Drug Target 2012; DOI: 10.3109/1061186X.2012.741136. 
67. Tibbitt MW, Dahlman JE, Langer R. Emerging frontiers in drug delivery. J Am Chem Soc 2016;138:704-17.

68. Weiser JR, Saltzman WM. Controlled release for local delivery of drugs: Barriers and models. J Control Release 2014;190:664-73.

69. Rejinold NS, Shin JH, Seok HY, Kim YC. Biomedical applications of microneedles in therapeutics: Recent advancements and implications in drug delivery. Expert Opin Drug Deliv 2016;13:109-31. Prausnitz MR. Engineering microneedle patches for vaccination and drug delivery to skin. Annu Rev Chem Biomol Eng 2017;8:177-200.

70. Quinn HL, Kearney MC, Courtenay AJ, McCrudden MT, Donnelly RF. The role of microneedles for drug and vaccine delivery. Expert Opin Drug Deliv 2014;11:1769-80.

71. Kim YC, Park JH, Prausnitz MR. Microneedles for drug and vaccine delivery. Adv Drug Deliv Rev 2012;64:1547-68.

72. van der Maaden K, Jiskoot W, Bouwstra J. Microneedle technologies for (trans)dermal drug and vaccine delivery. J Control Release 2012;161:645-55.

73. Daddona PE, Matriano JA, Mandema J, Maa YF. Parathyroid hormone (1-34)-coated microneedle patch system: Clinical pharmacokinetics and pharmacodynamics for treatment of osteoporosis. Pharm Res 2011;28:159-65.

74. Marshall S, Sahm LJ, Moore AC. The success of microneedlemediated vaccine delivery into skin. Hum Vaccin Immunother 2016;12:2975-83

75. Skountzou I, Compans RW. Skin immunization with influenza vaccines. Curr Top Microbiol Immunol 2015;386:343-69.

76. Suh H, Shin J, Kim YC. Microneedle patches for vaccine delivery. Clin Exp Vaccine Res 2014;3:42-9.

77. Arya J, Prausnitz MR. Microneedle patches for vaccination in developing countries. J Control Release 2016;240:135-41.

78. Henry S, McAllister DV, Allen MG, Prausnitz MR. Microfabricated microneedles: A novel approach to transdermal drug delivery. J Pharm Sci 1998;87:922-5.

79. Matriano JA, Cormier M, Johnson J, Young WA, Buttery M, Nyam K, et al. Macroflux microprojection array patch technology: A new and efficient approach for intracutaneous immunization. Pharm Res 2002;19:63-70

80. Donnelly RF, Mooney K, Caffarel-Salvador E, Torrisi BM, Eltayib E, McElnay JC, et al. Microneedle-mediated minimally invasive patient monitoring. Ther Drug Monit 2014;36:10-7.

81. Kim YC, Chiang B, Wu X, Prausnitz MR. Ocular delivery of macromolecules. J Control Release 2014;190:172-81.

82. Pettis RJ, Harvey AJ. Microneedle delivery: Clinical studies and emerging medical applications. Ther Deliv 2012;3:357-71

83. McCrudden MT, McAlister E, Courtenay AJ, González-Vázquez P, Singh TR, Donnelly RF, et al. Microneedle applications in improving skin appearance. Exp Dermatol 2015;24:561-6.

84. Bolognia JL, Jorizzo JL, Schaffer JV, editors. Dermatology. $3^{\text {rd }}$ ed. Philadelphia, PA: Saunders; 2012

85. Pastore MN, Kalia YN, Horstmann M, Roberts MS. Transdermal patches: History, development and pharmacology. Br J Pharmacol 2015;172:2179-209.

86. Blickenstaff NR, Coman G, Blattner CM, Andersen R, Maibach HI. Biology of percutaneous penetration. Rev Environ Health 2014;29:145-55.

87. Prausnitz MR, Langer R. Transdermal drug delivery. Nat Biotechnol 2008;26:1261-8.

88. Choy YB, Prausnitz MR. The rule of five for non-oral routes of drug delivery: Ophthalmic, inhalation and transdermal. Pharm Res 2011;28:943-8

89. Harvey AJ, Kaestner SA, Sutter DE, Harvey NG, Mikszta JA, Pettis RJ, et al. Microneedle-based intradermal delivery enables rapid lymphatic uptake and distribution of protein drugs. Pharm Res 2011;28:107-16.

90. Gill HS, Kang SM, Quan FS, Compans RW. Cutaneous immunization: An evolving paradigm in influenza vaccines. Expert Opin Drug Deliv 2014;11:615-27.

91. Donnelly RF, Moffatt K, Alkilani AZ, Vicente-Pérez EM, Barry J, McCrudden MT, et al. Hydrogel-forming microneedle arrays can be effectively inserted in skin by self-application: A pilot study centred on pharmacist intervention and a patient information leaflet. Pharm Res 2014;31:1989-99.

92. Norman JJ, Arya JM, McClain MA, Frew PM, Meltzer MI, Prausnitz MR, et al. Microneedle patches: Usability and acceptability for self-vaccination against influenza. Vaccine 2014;32:1856-62.

93. Baptista A, Teixeira I, Romano S, Carneiro AV, Perelman J. The place of DPP-4 inhibitors in the treatment algorithm of diabetes Type 2: A systematic review of cost-effectiveness studies. Eur J Health Econ
2017; 18:937-65.

94. Kermode M. Unsafe injections in low-income country health settings: Need for injection safety promotion to prevent the spread of bloodborne viruses. Health Promot Int 2004;19:95-103.

95. Lee BY, Bartsch SM, Mvundura M, Jarrahian C, Zapf KM, Marinan K, et al. An economic model assessing the value of microneedle patch delivery of the seasonal influenza vaccine. Vaccine 2015;33:4727-36.

96. Kartoglu U, Milstien J. Tools and approaches to ensure quality of vaccines throughout the cold chain. Expert Rev Vaccines 2014; $13: 843-54$.

97. Mistilis MJ, Joyce JC, Esser ES, Skountzou I, Compans RW, Bommarius AS, et al. Long-term stability of influenza vaccine in a dissolving microneedle patch. Drug Deliv Transl Res 2017;7:195-205.

98. Vrdoljak A, Allen EA, Ferrara F, Temperton NJ, Crean AM, Moore AC, et al. Induction of broad immunity by thermostabilised vaccines incorporated in dissolvable microneedles using novel fabrication methods. J Control Release 2016;225:192-204.

99. Hirobe S, Azukizawa H, Hanafusa T, Matsuo K, Quan YS, Kamiyama F, et al. Clinical study and stability assessment of a novel transcutaneous influenza vaccination using a dissolving microneedle patch. Biomaterials 2015;57:50-8.

100. Pearson FE, McNeilly CL, Crichton ML, Primiero CA, Yukiko SR, Fernando GJ, et al. Dry-coated live viral vector vaccines delivered by nanopatch microprojections retain long-term thermostability and induce transgene-specific $\mathrm{T}$ cell responses in mice. PLoS One 2013;8:e67888.

101. Ameri M, Daddona PE, Maa YF. Demonstrated solid-state stability of parathyroid hormone $\mathrm{PTH}(1-34)$ coated on a novel transdermal microprojection delivery system. Pharm Res 2009;26:2454-63.

102. Liu L, Wang Y, Yao J, Yang C, Ding G. A minimally invasive micro sampler for quantitative sampling with an ultrahigh-aspect-ratio microneedle and a PDMS actuator. Biomed Microdevices 2016;18:59.

103. Sridhar S, Maleq N, Guillermet E, Colombini A, Gessner BD. A systematic literature review of missed opportunities for immunization in low- and middle-income countries. Vaccine 2014;32:6870-9.

104. Clements CJ, Larsen G, Jodar L. Technologies that make administration of vaccines safer. Vaccine 2004;22:2054-8.

105. Gill HS, Prausnitz MR. Does needle size matter? J Diabetes Sci Technol 2007;1:725-9.

106. Hogan ME, Kikuta A, Taddio A. A systematic review of measures for reducing injection pain during adult immunization. Vaccine 2010;28:1514-21

107. Vicente-Pérez EM, Quinn HL, McAlister E, O’Neill S, Hanna LA, Barry JG, et al. The use of a pressure-indicating sensor film to provide feedback upon hydrogel-forming microneedle array self-application in vivo. Pharm Res 2016;33:3072-80.

108. Birchall JC, Clemo R, Anstey A, John DN. Microneedles in clinical practice - an exploratory study into the opinions of healthcare professionals and the public. Pharm Res 2011;28:95-106.

109. Mikolajewska P, Donnelly RF, Garland MJ, Morrow DI, Singh TR, Iani $\mathrm{V}$, et al. Microneedle pre-treatment of human skin improves 5 -aminolevulininc acid (ALA)- and 5-aminolevulinic acid methyl ester (MAL)-induced ppIX production for topical photodynamic therapy without increase in pain or erythema. Pharm Res 2010;27:2213-20.

110. Ding Z, Verbaan FJ, Bivas-Benita M, Bungener L, Huckriede A, van den Berg DJ, et al. Microneedle arrays for the transcutaneous immunization of diphtheria and influenza in BALB/c mice. J Control Release 2009:136:71-8.

111. Wermeling DP, Banks SL, Hudson DA, Gill HS, Gupta J, Prausnitz MR, et al. Microneedles permit transdermal delivery of a skin-impermeant medication to humans. Proc Natl Acad Sci U S A 2008;105:2058-63.

112. Brogden NK, Banks SL, Crofford LJ, Stinchcomb AL. Diclofenac enables unprecedented week-long microneedle-enhanced delivery of a skin impermeable medication in humans. Pharm Res 2013;30:1947-55.

113. Haj-Ahmad R, Khan H, Arshad MS, Rasekh M, Hussain A, Walsh S, et al. Microneedle coating techniques for transdermal drug delivery. Pharmaceutics 2015;7:486-502.

114. Gill HS, Prausnitz MR. Coated microneedles for transdermal delivery. J Control Release 2007;117:227-37.

115. Edens C, Collins ML, Goodson JL, Rota PA, Prausnitz MR. A microneedle patch containing measles vaccine is immunogenic in non-human primates. Vaccine 2015;33:4712-8.

116. DeMuth PC, Li AV, Abbink P, Liu J, Li H, Stanley KA, et al. Vaccine delivery with microneedle skin patches in nonhuman primates. Nat Biotechnol 2013;31:1082-5.

117. Kommareddy S, Baudner BC, Oh S, Kwon SY, Singh M, O'Hagan DT, et al. Dissolvable microneedle patches for the delivery of cell-culture- 
derived influenza vaccine antigens. J Pharm Sci 2012;101:1021-7.

118. Lee JW, Park JH, Prausnitz MR. Dissolving microneedles for transdermal drug delivery. Biomaterials 2008;29:2113-24.

119. Donnelly RF, Singh TR, Garland MJ, Migalska K, Majithiya R, McCrudden CM, et al. Hydrogel-forming microneedle arrays for enhanced transdermal drug delivery. Adv Funct Mater 2012;22:4879-90.

120. Singh TR, Dunne NJ, Cunningham E, Donnelly RF. Review of patents on microneedle applicators. Recent Pat Drug Deliv Formul 2011;5:11-23.

121. Davis SP, Landis BJ, Adams ZH, Allen MG, Prausnitz MR. Insertion of microneedles into skin: Measurement and prediction of insertion force and needle fracture force. J Biomech 2004;37:1155-63.

122. Crichton ML, Ansaldo A, Chen X, Prow TW, Fernando GJ, Kendall MA, et al. The effect of strain rate on the precision of penetration of short densely-packed microprojection array patches coated with vaccine. Biomaterials 2010;31:4562-72

123. Yan G, Warner KS, Zhang J, Sharma S, Gale BK. Evaluation needle length and density of microneedle arrays in the pretreatment of skin for transdermal drug delivery. Int J Pharm 2010;391:7-12.

124. Gill HS, Denson DD, Burris BA, Prausnitz MR. Effect of microneedle design on pain in human volunteers. Clin J Pain 2008;24:585-94.

125. Abdul M, Hajera M. Digitalisation and automation in pharmaceuticals from drug discovery to drug administration. Int J Pharm Pharm Sci 2018;2018:1-10.

126. Marin SH, et al. A prospective study: Knowledge assessment and patient care of diabetic foot ulcer patients in tertiary care hospital. Int J Pharm Pharm Sci 2017;28:104-10.

127. Agus K, et al. The effects of physical exercise on the insulin-dependent diabetes mellitus subjects using the modified minimal model. In J Pharm Pharm Sci 2017;1:179-86. 